\title{
Leadership Approach: The Role of Traits, Styles, Skills, and Culture in a Cebuano University
}

\author{
Anna Lou C. Cabuenas ${ }^{\circledR}$, Jedidiah K. Singco $\mathbb{D}^{\circledR}$, Rosemarie C. Español $\mathbb{1}$ \\ University of the Visayas, Cebu City, Philippines \\ Email: annaloucabuenas@yahoo.com, jedisingco.comm1@gmail.com, rosemarie.espanol@gmail.com
}

How to cite this paper: Cabuenas, A. L. C., Singco, J. K., \& Español, R. C. (2021). Leadership Approach: The Role of Traits, Styles, Skills, and Culture in a Cebuano University. Journal of Human Resource and Sustainability Studies, 9, 385-396. https://doi.org/10.4236/jhrss.2021.93024

Received: June 17, 2021

Accepted: August 9, 2021

Published: August 12, 2021

Copyright $\odot 2021$ by author(s) and Scientific Research Publishing Inc. This work is licensed under the Creative Commons Attribution International License (CC BY 4.0).

http://creativecommons.org/licenses/by/4.0/

\section{(c) (i) Open Access}

\begin{abstract}
The purpose of this study was to examine the University heads of departments' leadership approaches and their views by conducting a survey on 17 university heads and directors within a Cebuano University. The survey with these leaders focused on their leadership attributes specifically their leadership traits, styles, and skills. The different Leadership Approach Inventory instruments created by Peter G. Northouse (2013) were utilized in this study wherein the respondents were asked to rate themselves along several statements that describe various key practices and characteristics associated with leadership. In addition, thematic analysis was conducted to explore the participants' personal philosophies as a leader, their perceptions of what a good leader ought to have, and their views on existing culture within the organization. Results showed that although majority of the participants possess traits related to extroversion, there appears to be a need to practice more discernment in dealing with personnel. Most of the department heads also showcase a people-centered leadership style, which suits Filipino culture. These were supported in the thematic analysis wherein the participants' views on good leadership centered on characteristics that deal with interpersonal relationships. In terms of skills, technical and human skills were more prominent over conceptual ability. Participants also stressed the importance of maintaining good relations with the administration for better accomplishment of goals.
\end{abstract}

\section{Keywords}

Leadership Approach, Leadership Styles, Leadership Skills, Leadership Characteristics, Organizational Culture 


\section{Introduction}

Effective leadership plays a significant role in the survival of every organization especially in the midst of transition. This study examined how behavioral approach and the social perception process operate in leadership with heterogeneous samples and the implications of this in leadership. This research identified the behavioral and social facets that leaders possess and intends to produce research findings aimed at shedding light on the roles of traits, skills, culture and expectations in perception and judgment of different people in leadership relationships.

Heads of offices in the workplace have their own perceptions and understanding of their leadership style or brand. By examining these self-perceptions and understanding how they exert an influence, leaders can learn how to shift their perceptions in order to improve their practices. The findings of the current study can therefore shed light on the leadership styles of heads in a Cebuano university, thus taking steps towards improvement and progress.

For this study, the current university was initially chosen because it is one of the oldest universities in the Philippines that has been existing since before World War II, and has celebrated its centennial anniversary. The primary aim of the researchers was to study the institution's best practices and organizational framework to understand how these have contributed to the way that the university has sustained itself this long. However, the nature of the research problem evolved after a series of preliminary interviews with some of the heads of office who disclosed that although documents for the institutional framework existed, the latter was never properly disseminated and implemented all these years. In fact, the institution's best practices have reportedly not been formalized because it has not been operating in the context of a clear-cut, implemented institutional system. This has resulted in the leaders of the various departments and colleges creating their own systems within their respective offices.

In spite of the absence of a unified institutional framework, many of the offices and departments have achieved major milestones such as passing national accreditation programs and producing exemplary outputs in their field. Other departments, however, seem to be left behind in the quest for growth. This contrast in organizational performance points to the possibility that leadership may play an important role in the progress of some departments and stagnation in others.

Given this context, the current study aims to determine the leadership traits, skills, and styles of the various heads of office in the university. Their personal philosophies as leaders and their perceptions of the university and workplace culture will also be examined. Afterwards, these leadership attributes will be analyzed in relation to the performance of their respective offices in recent years.

According to Solis, Kupczynski and Mundy (2011) "efforts to gain a better understanding of leadership have led scholars to take interest in the study of leadership in academic settings". Reynolds (2010) also emphasized good leadership as a crucial ingredient in the success of an educational institution. $\mathrm{He}$ 
acknowledged that gaining success in schools requires effective leadership.

Leadership is a general concept. Maxwell (2013) mentioned that if one asks several people to define leadership, he/she would receive several different answers. He defined leadership as the ability to obtain followers. When investigating leadership, Northouse (2013) wrote, "leadership is a process whereby an individual influences a group of individuals to achieve a common goal". Eddy (2012) summed up the leadership investigations by stating, "the literature on leadership is as plentiful as it is diverse. Several definitions of leadership, as well as theories of leadership, exist. Some authors strive for a concise definition and understanding of leadership".

Rebore (2011) added to Eddy's idea by writing "there are numerous leadership theories that are currently in vogue". He mentioned some of the theories such as "Seven Habits of Highly Effective People", "Total Quality Management", and "Transcendental Leadership". Based on the literature, the emergent themes surrounding prominent theories of leadership are leadership traits, leadership styles, and contingency leadership.

\section{Statement of the Problem}

The purpose of this descriptive study was to investigate the university heads of departments' perceptions regarding their leadership approaches in their departments. The research questions are as follows:

1) What are the prevailing leadership attributes of the various heads of offices in the university in terms of their:

a) Personal characteristics,

b) Skills, and

c) Leadership style?

2) What is their personal philosophy as a leader?

3) For them, what are the top three traits or values that a leader should possess?

4) How did they deal with the existing culture in their:

a) Department, and

b) University?

\section{Methodology}

The university is comprised of twenty four middle management offices. In total, there are eleven males and thirteen females. All members of the population were identified as the respondents of the study. Only 17 of the survey instruments were returned, which was $70.8 \%$ of the total population of departments' heads perceptions of leadership practices at the university.

In this study, each of the heads of departments was asked to complete a set of scales from Peter Northouse's (2013) book on Leadership: Theory and Practice. The survey questionnaire was divided into five sections. Section 1 was composed of the demographic profile, requesting respondents to provide data on gender, 
sex, current position held, and length of employment.

Section 2 was composed of the Leadership Trait Questionnaire that had fourteen statements, each stating various personal characteristics of leadership (i.e. "perceptive", "confident", "self-assured", "diligent", etc.). The scale is administered by letting the leader answer the scale (thereby rating themselves), and by letting at least 2 of their staff members rate them as well. The scores for each item is calculated as the average of the heads' self-ratings and the ratings of their staff. For this questionnaire, reliability statistics cannot be computed because each item rates a different personal characteristic and the scoring is also done per item, not the scale as a whole.

Section 3 is composed of the Leadership Style Assessment containing twenty items. Half of the items are intended to measure task-orientation leadership, while the other half is composed of items that measure a relationship-oriented leadership style. Cronbach's Alpha reliability index was used to calculate reliability for each of the two subscales. The Task-Orientation subscale had an index of $\alpha=$ 0.891 while the Relationship-Orientation subscale index was calculated to be $\alpha=$ 0.929 , which indicates that these scales meet requirements for reliability in research.

Section 4 contains the Leadership Skills Assessment Scale with eighteen items, divided into 3 subscales (technical, human, and conceptual) identifying the leadership skills which are considered to be the key practices for effective leaders. Cronbach's Alpha for the subscales also showed that all of them are reliable enough for use in research. The technical skills subscale scored $\alpha=0.804$, the human skills subscale scored $\alpha=0.794$, while the conceptual skills subscale scored $\alpha=0.752$.

Sections 2 to 4 were all in 5-point Likert scale format. The survey instrument was distributed to all 24 department heads of which only 17 answered the questionnaire.

Qualitative research data were also collected through written accounts of the participants' perceptions regarding their leadership approaches in their departments. Section 5 of the questionnaire therefore consisted of open-ended questions were also included to delve deeper into the practices executed by each leader. The informants were asked to write down their perceptions regarding their leadership approaches in their departments, their beliefs on the necessary traits that leaders ought to have, and their personal views on dealing with organizational culture.

Thematic analysis was then used to analyze the qualitative, written answers of the informants. Phrases were coded into themes based on the research objectives. To ensure reliability in the coding and validity in the content, themes were initially coded by one researcher and codes were reviewed afterwards by the other researchers.

\section{Results and Discussion}

Data were collected from a total of 17 managers and/or heads of office who 
agreed to take part in the study, along with 40 personnel from their departments. The scores from the survey questionnaire were tallied, encoded, and analyzed as follows.

Traits Assessment. For this section, the heads of office were asked to rate themselves across 14 traits. At least two of their personnel were also asked to rate them using the same scale. After analyzing the means, the department heads scored an average of $4.45(\mathrm{SD}=0.54)$ in their self-ratings while their employees rated them with $4.2(\mathrm{SD}=1.05)$ on average. Table 1 shows the breakdown of these scores.

While it may be pointed out that the managers tended to score themselves higher than their personnel did, it is also clear that the scores. Therefore, it may be concluded that both parties rated the heads of office in a relatively objective manner.

Out of the 14 traits, the following were the five most highly-rated and bottom three traits taking into account both self-ratings and scores gathered from office personnel.

As seen in Table 2, the top traits of the heads of office are centered on typical extrovert characteristics. Leaders in the university see themselves (and are seen by their personnel) as friendly and approachable figures who work on their tasks, are self-confident, and can be trusted. Interestingly however, the bottom rated traits appear to contradict the high-rated traits.

Table 1. Self-ratings versus staff ratings.

\begin{tabular}{|c|c|c|c|}
\hline Heads of Office & $\begin{array}{l}\text { Average of } \\
\text { Self-Ratings }\end{array}$ & $\begin{array}{c}\text { Average of } \\
\text { Staff-Ratings }\end{array}$ & $\begin{array}{c}\text { Average } \\
\text { Overall Rating }\end{array}$ \\
\hline 1 & 4.71 & 4.15 & 4.43 \\
\hline 2 & 5.00 & 4.71 & 4.86 \\
\hline 3 & 5.00 & 7.79 & 6.40 \\
\hline 4 & 4.00 & 3.67 & 3.84 \\
\hline 5 & 4.21 & 3.79 & 4.00 \\
\hline 6 & 4.79 & 4.46 & 4.63 \\
\hline 7 & 4.79 & 4.21 & 4.50 \\
\hline 8 & 4.36 & 3.39 & 3.88 \\
\hline 9 & 4.50 & 4.82 & 4.66 \\
\hline 10 & 3.29 & 4.62 & 3.95 \\
\hline 11 & 4.29 & 4.81 & 4.55 \\
\hline 12 & 4.71 & 4.21 & 4.46 \\
\hline 13 & 4.00 & 3.93 & 3.96 \\
\hline 14 & 4.00 & 3.93 & 3.96 \\
\hline 15 & 4.93 & No Data & 4.93 \\
\hline 16 & 4.36 & No Data & 4.36 \\
\hline 17 & 4.71 & No Data & 4.71 \\
\hline
\end{tabular}

$\mathrm{N}=17$. 
Table 2. Ratings of leadership traits.

\begin{tabular}{cccc}
\hline Traits & M & SD \\
\hline Outgoing & 4.49 & 0.69 \\
Top Traits & Self-confident & 4.48 & 0.74 \\
Filigent & 4.45 & 0.69 \\
Friendly & 4.41 & 0.73 \\
Trustworthy & 4.38 & 0.73 \\
Empathic & 4.34 & 0.64 \\
Conscientious & 4.30 & 0.69 \\
Articulate & 4.28 & 0.80 \\
Persistent & 4.24 & 0.96 \\
Determined & 4.20 & 0.75 \\
Dependable & 4.20 & 0.80 \\
Pottom Traits & Serceptive & 4.02 & 0.9 \\
& Self-assured & 4.14 & 0.86 \\
& & 4.18 & 0.72 \\
\hline
\end{tabular}

$\mathrm{N}=57$.

For example, leaders are rated as self-confident, but not as self-assured (it must also be noted that the mean scores between high and low ratings do not largely differ). Going back to the questionnaire, self-confidence is defined as "believing in oneself and his/her ability". Self-assurance on the other hand is defined as "being secure of oneself and free of doubts". From these definitions, we may conclude that the heads of office generally exude confidence in themselves, but sometimes exhibit insecurity and doubts. This is of course understandable as being in a leadership position entails that one is confident, but not too overconfident.

Additionally, although leaders rated highly as being outgoing and friendly, they also scored relatively lower in terms of being perceptive and sensitive. Since the leadership trait questionnaire was primarily made as an instrument so assess one's strength and weaknesses, we can conclude that the heads of office need to improve the quality of their interpersonal relationships with personnel in terms of "looking beneath the surface". Although personnel in the office may generally display a pleasing disposition and jovial attitude, it is crucial that the head of office knows how to be sensitive to their staff and display tact in handling discussions, negotiations, or meetings. It may be fitting to recommend that the university's upper-level managers practice more discernment and insight in their interactions with their personnel. After all, friendliness and being outgoing are indeed admirable traits but in themselves are not enough to effectively and efficiently run an office. 
Leadership Style. The result of the study pertaining to leadership style showed that majority of the heads of office in the said institution tend to be people-oriented $(\mathrm{M}=44.29, \mathrm{SD}=4.64)$ rather than task-oriented $(\mathrm{M}=43.94, \mathrm{SD}=5.42)$. Table 3 below shows the results.

They focus on making their subordinates feel comfortable with themselves and they engaged in a relationship behavior in influencing their colleagues such as helping the group members get along with each other, establishing active communication with the group, responding favorably to suggestions about how to solve problems, and being friendly with the group. This implies that leaders are fostering positive relationship among its members. This prevailing leadership style could be influenced by the Filipino culture which is collective, communal, and focuses more on interpersonal relationships.

Based on the results of the GLOBE Study of 62 Societies (2004), the Philippines was one of the countries in Southern Asia that exhibited a high score on humane orientation and in-group collectivism. This simple means that Filipinos has a culture that encourages and rewards people for being fair, altruistic, generous, caring, and kind to others. This also emphasizes sensitivity to others, social support and community values. Furthermore, this implies that majority of the Filipino leaders' leadership styles is still associated with modesty and sensitivity that made them effective in dealing with their subordinates. These characteristics appear to still be relevant today, as reflected in the results of the current study.

However, it must also be noted that being too focused on a relationship orientation may pose some problems in terms of establishing and sustaining efficient and effective operations in a department. For example, rewards and reprimands should ideally be based on how well people perform in their respective tasks, not in how well they relate to their peers, superiors, or subordinates. Therefore; leaders must learn how to strike a healthy balance between being relationshiporiented and task-oriented.

Leadership Skills. In personal assessment of management leaders, the results of the data gathered revealed that these leaders have different levels of competence in terms of technical, human, and conceptual skills.

It is interesting to note that leaders in the middle management who are expected to be more competent in terms of human and conceptual skills are found to be most competent in human skills $(M=26, S D=3.06)$, followed by technical skills $(\mathrm{M}=25.88, \mathrm{SD}=2.78)$ and least competent in conceptual skills $(\mathrm{M}=$ 24.75 , SD $=3.19$ ). As stated by Northouse (2013), "Leaders are more effective when their skills match their management level."

Table 3. Means of leadership styles.

\begin{tabular}{ccccc}
\hline Subscale & M & SD & Variance & N of Items \\
\hline Task-Orientation & 43.94 & 5.42 & 21.56 & 10 \\
Relationship-Orientation & 44.29 & 5.417 & 29.35 & 10
\end{tabular}


In middle management, the ability to effectively conceptualize becomes more crucial because leaders are required to work with ideas and concepts. Unlike rank-and-file employees where technical skills are the most important, upper management dictates that one has the ability to create strategic plans and do their best to make sure that these push through. This kind of goal requires the ability to work with abstractions, hypothetical notions, and decide upon the best course of action given limited resources and time constraints.

Based on the results, the heads of office in the university are well-equipped in human skills. This supports the results found in leadership traits and styles, wherein the topmost traits exhibited by the leaders all point to extrovert, outgoing characteristics. The prevailing leadership style is also more centered on a relationship orientation compared to a task orientation. Therefore, it is no wonder that human skills are also in the forefront of the middle managers' leadership skills.

However it must be pointed out that managing effective and efficient office operations cannot survive only on human and technical skills alone. After all, the latter can be easily learned if necessary, and in the first place it is the job of office personnel to accomplish technical tasks. Leaders are responsible for directing their staff instead of accomplishing these kinds of tasks themselves. Therefore, it may be wise to recommend that the heads of office for this study should consider practicing their conceptual abilities, specifically those that require them to generate strategic plans and decide on appropriate courses of action that push these plans through.

In addition to the quantitative data gathered, thematic analysis was also conducted and information gleaned from the extracted themes was consolidated to produce an overall idea about the participants' views and beliefs on leadership.

Personal Philosophy as a Leader. The first question asked the informants to narrate their personal philosophy as a leader.

From the informants' answers, a total of three major themes emerged. The first major theme was being a good role model. Most of the informants said that a leader must become the change he wants to see in the team or organization. They further mentioned that "actions speak louder than words" and that for them in order to motivate the team, a leader must start seeing himself as a role model and as a good example to others.

"A leader is a good manager and a role-model. (M, 41)".

"As a leader I must be morally upright, empower and inspire other people in a way I can develop my leadership to achieve things beyond expectation. (F, 42)".

"A leader works hard and leads by example through action. (M, 46)".

The next major theme was inspiring and motivating people. Most of the informants agreed that great leaders motivate people. They also believed that their employees determine a company's success or failure. Further interviews with the informants also revealed that based from their experiences, what propels and sustains a successful organization is its diverse team of talented, motivated employees. 
“... Achieving goals and vision of the organization by inspiring people to be empowered to become great and valuable individuals belonging in this particular community and environment. (M, 43)".

"A leader motivates, innovates, inspires and put to action what has been collaboratively discussed. (F, 64)".

"A leader is a motivator to [his/her] subordinates. (F, 55)".

The third major theme that emerged was working harmoniously with colleagues. Informants believed that having a good harmonious relationship with the co-employees is a must because not only that it brings a good working environment, but it encourages better association as well. They further mentioned during the interviews conducted by the researchers that in building a working relationship with office mates, it is best to put one's best foot forward, but without concealing the real "you". Some informants also mentioned that being true to everyone is important, but a healthy balance should be observed by dealing with one's personnel professionally.

"As a leader, I would like to foster a good working relationship with my peers. By doing so, [I] will be able to gain their cooperation which will help the department attain its objectives. (F, 48)".

"A leader is somebody who can work harmoniously with others in spite of all odds in our work. (F, 64)".

It must be noted that the themes extracted support the data gathered in terms of prevailing leadership traits, styles, and skills wherein friendliness and interpersonal skills were highlighted. For the heads of office in the university, their relationship with colleagues and personnel is of utmost importance and defines their personal brand of leadership. Additionally, it is interesting to note that none of the participants mentioned anything about foregoing or sacrificing interpersonal relationships for the sake of achieving goals.

Top Three Traits or Values that a Leader should Possess. For this specific research question, the informants were asked specifically about the top three traits or values that a leader should possess. From the informants' answers, a total of three major themes emerged.

The first major theme was being strong-willed. Informants believed that being strong-willed is one of the important leadership traits that great leaders should possess. They also mentioned that leaders must have a clear vision of the organization's preferred future, even when others cannot see it.

"[A leader should have] strong determination. (F, 55)".

"[I am] firm in my decisions. (F, 42)".

"[A leader should be] strong-willed. (F, 48)".

The next major theme was humility. Most of the informants believed that if leaders are humble and unassuming people, the world becomes a better place. They also stressed out the importance and virtue of humility and mentioned that humble leaders improve the performance of a company in the long run because they create more collaborative environments. 
"[A leader should be] humble but firm in decision-making. (F, 64)".

"[A leader should be] humble. [He must] know when to decide. (F, 30)".

"[A leader should be] humble. $(\mathrm{M}, 36)$ ".

Another theme was the importance of being open-minded. Based from the informant's answers, they believed that in order to survive whatever trials and tribulations the future might bring, leaders need to learn to adapt. They also stressed out that leaders must learn to be more open minded, which means being receptive to the views, ideas and knowledge of others.

"[A leader should be] a good listener and accepts subordinates' suggestions. (F, 21)".

"[A leader should be] open-minded. (F, 64)".

Of the three major themes which emerged, one is relatively goal-oriented (being strong-willed) while the others once again are hinged on interpersonal relationships (humility and open-mindedness). This is an interesting combination of valued leadership traits. For this group of participants, the findings suggest that firmness is valued as long as it does not invalidate the other personnel in the department.

Dealing with Existing Culture in the Department. The first question asked the informants to narrate how they deal with the existing culture in their department. From the four informants' answers, a total of three major themes emerged.

The first major theme was being open-minded and understanding. The informants really believed that leaders who discipline themselves to look at the world around them with an open mind stand on a balcony where they are better-positioned to see windows of opportunity. They also stressed out that they can see new pathways and patterns that will lead them down the road to success if they try to understand their colleagues.

"I look at my faculty as my colleagues, [I] am open to suggestions [and] criticisms for me to learn the art of leadership. (F, 58)".

"I just try to understand and listen to all to harmonize the college. (F, 43)".

The next major theme was always aspiring for excellence in every endeavor. Further interviews revealed that most of the informants aimed to strive for excellence, not perfection. Most of them use their talents, abilities, and skills in the best way possible because for them accomplishing tasks in an excellent fashion gives them great pride and self-esteem, since the quality of their work is a measure of the quality of themselves.

"[I] always aspire for excellence in every endeavor. (F, 64)".

“... [I] work for excellence [specially that] the program requires promotion. $(\mathrm{F}, 55)$ ".

The third major theme was being patient. For the informants, great leaders know that having excellent skills in patience will create the best kind of team since it is an underpinning of good leadership.

"[I] am patient in spite of all the adversities in the workplace. (F, 64)".

"[I] am patient and treat others fairly. (F, 36)".

Dealing with Existing Organizational Culture. For this specific research ques- 
tion, the informants were asked to narrate how they deal with the existing culture in the university. From the informants' answers, only one major theme emerged. This was asking for administration's support.

"All of the challenges [that] I had ever since I held this position made me stronger with the help of the personnel... [and also] with the support of the administration. (F, 58)".

"[because of the] highly centralized administrative support. (F, 55)".

Most of the respondents agreed that they were able to deal with the existing culture of the university because of the full administration support that they receive. They further added that they are thankful because the administration was able to establish systems that protect and sustain very important operational duties to meet the needs of their respective departments.

\section{Conclusion}

Given that the university at the time of this study still has not fully implemented a unified institutional framework, it is nevertheless interesting to analyze the characteristics of its appointed middle managers, or heads of office.

The results reveal that majority of the leaders are able to exhibit good interpersonal skills and maintain amicable relations with their office personnel. This is apparently rooted in their own personal philosophies on what traits good leaders should possess, philosophies which are most likely influenced by Filipino culture which stresses socialization and is strongly collectivist. However, a healthy balance must be observed between being relationship-oriented and task-oriented. It appears that although the leaders who participated in the study display above average "human skills", their conceptual abilities and task-orientation are put on the line. In middle management, conceptual skills are more important than human and technical skills because the position demands the ability to be a visionary: to set goals, and make sure that these goals are achieved.

On a final note, it is important to emphasize that some of the key limitations of this paper include the relatively small sample size (due to only a few heads who consented to participate in the study), and the restriction of the data analysis to simple descriptive statistics. Future researchers may consider doing longitudinal studies or in-depth case studies to investigate the dynamics within departments whose leaders put more importance upon interpersonal relationships rather than conceptualization and achievement of goals.

\section{Conflicts of Interest}

The authors declare no conflicts of interest regarding the publication of this paper.

\section{References}

Eddy, P. L. (2012). Community College Leadership: A Multidimensional Model for Leading Change. Stylus Publishing, LLC. 
Maxwell, J. C. (2013). Right to Lead: Learning Leadership through Character and Courage. Sourcebooks, Inc.

Northouse, P. G. (2013). Leadership: Theory and Practice. Sage Publications.

Rebore, R. W. (2011). The Essentials of Human Resources Administration in Education. Pearson Higher Education.

Reynolds, B. (2010). Principles to Enable Leaders to Navigate the Harsh Realities of Crisis and Risk Communication. Journal of Business Continuity \& Emergency Planning, 4, 262-273.

Solis, F., Kupczynski, L., \& Mundy, M.-A. (2011). A Profile of Faculty Leadership Behavior at One South Texas Community College. International Journal of Educational Leadership Preparation, 6, 1-17. 